\title{
Cytokine Regulation from Human Peripheral Blood Leukocytes Cultured In Vitro with Silver Doped Bioactive Glasses Microparticles
}

\author{
Jefferson Muniz de Lima $\mathbb{D}^{\mathbb{D}},{ }^{1}$ Edlainne Pinheiro Ferreira $(\mathbb{D}){ }^{1}$ \\ Roberta Ferreti Bonan $\left(\mathbb{D},{ }^{1}\right.$ David Nascimento Silva-Teixeira, ${ }^{2}$ Luiz Ricardo Goulart $\mathbb{D}^{\mathrm{D}},{ }^{3,4}$ \\ Joelma Rodrigues de Souza, ${ }^{1,5}$ Eliton Souto de Medeiros, ${ }^{6}$ \\ Paulo Rogério Ferreti Bonan $\mathbb{D}^{1},{ }^{1}$ and Lúcio Roberto Cançado Castellano $\mathbb{D}^{1}$ \\ ${ }^{1}$ Human Immunology Research and Education Group-GEPIH, Escola Técnica de Saúde da UFPB, \\ Universidade Federal da Paraíba, João Pessoa, Brazil \\ ${ }^{2}$ Institute of Health Sciences, Department of Clinical Medicine, Universidade Federal do Triângulo Mineiro Federal, Uberaba, Brazil \\ ${ }^{3}$ Laboratory of Nanobiotechnology, Institute of Genetics and Biochemistry, Universidade Federal de Uberlandia, Uberlandia, Brazil \\ ${ }^{4}$ Department of Medical Microbiology and Immunology, University of California Davis, Davis, CA, USA \\ ${ }^{5}$ Department of Physiology and Pathology, Universidade Federal da Paraíba, João Pessoa, Brazil \\ ${ }^{6}$ Materials and Biosystems Laboratory, Universidade Federal da Paraíba, João Pessoa, Brazil
}

Correspondence should be addressed to Lúcio Roberto Cançado Castellano; luciocastellano@gmail.com

Received 18 March 2019; Revised 12 April 2019; Accepted 21 April 2019; Published 11 June 2019

Guest Editor: Francesca Salamanna

Copyright (C) 2019 Jefferson Muniz de Lima et al. This is an open access article distributed under the Creative Commons Attribution License, which permits unrestricted use, distribution, and reproduction in any medium, provided the original work is properly cited.

\begin{abstract}
Bioactive glasses (BG) applications include tissue engineering for bone regeneration, coating for implants, and scaffolds for wound healing. BG can be conjugated to ions like silver, which might add some antimicrobial properties to this biomaterial. The immunomodulatory activity of ion-doped bioactive glasses particles was not investigated before. The aim of this work was to evaluate the cytotoxic and immunomodulatory effect of BG and silver-doped bioactive glass (BGAg) in human peripheral blood cells. BG and BGAg samples belonging to the system $58 \mathrm{SiO}_{2} \bullet(36-\mathrm{x}) \mathrm{CaO} \cdot 6 \mathrm{P}_{2} \mathrm{O}_{5} \cdot \mathrm{xAg}_{2} \mathrm{O}$, where $\mathrm{x}=0$ and 1 mol\%, respectively, were synthesized via sol-gel method and characterized. Cytotoxicity, modulation of cytokine production (TNF- $\alpha$, IL- $1 \beta$, IL-6, IL4, and IL-10), and oxidative stress response were investigated in human polymorphonuclear cells (PMNs) and peripheral blood mononuclear cells (PBMCs) cultures. Cell viability in the presence of BG or BGAg was concentration-dependent. In addition, BGAg presented higher PBMCs toxicity (LC50 $=0.005 \%)$ when compared to BG (LC50 $=0.106 \%)$. Interestingly, interleukin 4 was produced by PBMCs in response to BG and BGAg in absence of phytohemagglutinin (PHA) and did not modulate PHA-induced cytokine levels. Subtoxic concentrations $(0.031 \%$ for BG and $0.0008 \%$ for BGAg) did not change other cytokines in PBMCs nor reactive oxygen species (ROS) production by PMN. However, BG and BGAg particles decreased zymosan-induced ROS levels in PMN. Although ion incorporation increased BG cytotoxicity, the bioactive glass particles demonstrated a in vitro anti-inflammatory potencial. Future studies are needed to clarify the scavenger potential of the BG/BGAg particles/scaffolds as well as elucidate the effect of the anti-inflammatory potential in modulating tissue growth in vivo.
\end{abstract}

\section{Introduction}

Bioactive glass (BG) consists of a $\mathrm{SiO}_{2}$ network, having $\mathrm{P}_{2} \mathrm{O}_{5}$ as an adjuvant and $\mathrm{CaO}$ and $\mathrm{Na} 2 \mathrm{O}$ as modifiers $[1,2]$. The bioactivity of this material allows its application in the field of regeneration and tissue engineering [3]. It can be used in a wide range of applications, such as bioactive fillers in bone regeneration [4], coating for implants, dental grafting $[5,6]$, and scaffold for tissue repair, with porous arrangements similar to trabecular bone [3,7]. BG is most used as hard tissue replacement material, although some studies show remarkable properties in soft tissues repair, as observed in 
decreased blood coagulation time, angiogenesis, and reduced wound healing time [8].

Recently, BGs have been associated with inorganic materials such as ions for nonbone therapeutic applications [9]. Silver-doped glasses showed antibacterial and antifungal effect against Escherichia coli, Staphylococcus aureus [1012], Pseudomonas aeruginosa, and Candida albicans [13] in comparison to neat BG. Such proprieties may minimize complications on bone surgery like bacterial infection by topical drug delivering in a controlled and continuous manner [14]. However, silver loading may increase hypersensitivity, chronic inflammation, and immune stimulation due to materials exposure [15].

The potential immunomodulatory activity of bioactive glasses has been tested before $[7,16]$. Results indicated that differences in immune response modulation are dependent on material composition or on a particular system from which the bioactive glasses are selected. Some samples indicated an ability to inhibit the secretion of inflammatory cytokines in the presence of an inflammatory stimulus [16]. However, the immunomodulatory activity of bioactive glasses doped with silver ions has not been investigated before. Little is known about the effects of $\mathrm{Ag}^{2+}$ on healthy primary cells of the human immune system. The complete understanding of the specific interactions and response dynamics of the immune system to different materials is still inconclusive, especially for health applications or safety recommendations [17]. Therefore, the aim of this work was to evaluate the cytotoxic and immunomodulatory effect of BG and silver-doped bioactive silica over human leukocytes.

\section{Materials and Methods}

2.1. BG Synthesis. Samples belonging to the system $58 \mathrm{SiO}_{2} \bullet(36-\mathrm{x}) \mathrm{CaO} \cdot 6 \mathrm{P}_{2} \mathrm{O}_{5} \cdot \mathrm{x} \quad \mathrm{Ag}_{2} \mathrm{O}$ with $\mathrm{x}=0$ or $1 \mathrm{~mol} \%$ (Neat BG and BGAg) were previously synthesized and fully characterized by physical-chemical analysis and gently provided by Pires et al. [18]. Briefly, hydrolysis and condensation of tetraethyl orthosilicate (TEOS), calcium nitrate tetrahydrate $\left(\mathrm{Ca}\left(\mathrm{NO}_{3}\right)_{2} \bullet 4 \mathrm{H}_{2} \mathrm{O}\right)$, triethyl phosphate (TEP; Sigma Aldrich), and silver nitrate $\left(\mathrm{AgNO}_{3}\right.$; PlatLab) were used to obtain the gels. The molar ratio of EtOH: TEOS was of 1:1. The other precursors were dissolved in distilled water. The $\mathrm{pH}$ of solutions was adjusted to 2 by addition of $\mathrm{HNO}_{3}$. The obtained gels were dried for 3 days at room temperature and 2 days in a drying oven, at $120^{\circ} \mathrm{C}$. The dried BG gels were heated up to $700^{\circ} \mathrm{C}$ for $1 / 2 \mathrm{~h}$, at a constant rate of $3^{\circ} \mathrm{C} \mathrm{min}^{-1}$. Herein, the glasses were passed through a 200-mesh British Standard Sieve (final particles diameter smaller than $74 \mu \mathrm{m}$ ). The samples synthesis was performed under aseptic conditions and the surface disinfection was made by exposure to germicidal UV light for 30 minutes [19].

Information regarding BG and BGAg characterization and composition are available at https://doi.org/10.1111/ ijag.12285. Briefly, the samples were characterized by scanning electron (SEM), atomic force (AFM) microscopy, X-ray diffraction (XRD), Fourier-transform Infrared (FTIR), and surface-enhanced Raman (Raman-SERS) spectroscopy. SEM and AFM images showed particles with irregular morphology and rough surface. XRD and FTIR analyses confirmed amorphous structure corresponding to BG formation, incipient crystallization, and the presence of $\mathrm{Si}-\mathrm{O}-\mathrm{Si}$ groups typical from glass structure even with silver inclusion within BG.

2.2. Samples. Materials and Methods section was structured following the minimal information about $\mathrm{T}$ cell assay [20] and this study was approved by local ethics committee. Initial blood samples were kindly provided by three male healthy volunteers following the inclusion criteria: seronegative for $\mathrm{HIV}$ and $\mathrm{HCV}$, vaccinated against $\mathrm{HBV}$ and with no signs or symptoms of acute infections at the time of blood sampling and leukocytes isolation. To ensure the safety of blood donors and maintenance of cell integrity, the specimen collection followed the guidelines established by the Clinical and Laboratory Standards Institute [21]. The healthy volunteers signed a written consent to participate according to the Helsinki Declaration of ethical guidelines.

2.3. Peripheral Blood Mononuclear Cells (PBMC) and Polymorphonuclear Neutrophil (PMN) Isolation and Stimulation. For PBMC and PMN isolation, $18 \mathrm{ml}$ of heparinized whole blood was collected by venipuncture and aliquots of $12 \mathrm{ml}$ and $9 \mathrm{ml}$ were processed by density gradient centrifugation. Two different ficoll densities were applied: Histopaque ${ }^{\circledR} 1077$, for PBMC separation, and Histopaque ${ }^{\circledR} 1119$ for PMN isolation (Sigma-Aldrich, St. Louis, USA) [22]. The buffy coats of PBMCs and PMNs were collected and washed three times with phosphate buffer and counted in Countess ${ }^{\circledR}$ FL Automated Cell Counter (Thermo Fisher Scientific, Waltham, USA) using Trypan blue (Sigma-Aldrich, St. Louis, USA) exclusion method. Cell suspensions (PBMC and PMNs) presented at least $95 \%$ cell viability and purity as determined by morphological examination of Giemsa-stained cytocentrifuged slides (Shandon, Pittsburgh, PA, USA). Cells were suspended in equal aliquots of $2 \times 10^{6} \mathrm{PBMC} / \mathrm{ml}$ and $10^{6}$ $\mathrm{PMN} / \mathrm{ml}$ in RPMI 1640 medium (Gibco, Life Technologies, UK) supplemented with $10 \%$ heat-inactivated fetal bovine serum, $1 \%$ PenStrep, and 20mM HEPES. All procedures were conducted at room temperature.

2.4. PBMCs Viability Assay. $100 \mu \mathrm{l}$ of PBMC's suspension was cultured in 96 black polystyrene wells flat bottom microplates (Greiner Bio- One, USA) and stimulated with $5 \mu \mathrm{g} / \mathrm{ml}$ of phytohemagglutinin (PHA-P; Sigma-Aldrich, St. Louis, USA) and incubated 1:1 with BG (range $1-0.0075 \% \mathrm{wt} / \mathrm{vl}$ ) or BGAg (range $1-0.0002 \% \mathrm{wt} / \mathrm{vl}$ ) in culture medium for 24 hours at $37^{\circ} \mathrm{C}$ in a humidified atmosphere at $5 \% \mathrm{CO}_{2}$.

Cell viability was measured using alamarBlue ${ }^{\circledR}$ according to kit protocol (Bio-Rad, Hercules, EUA). Fluorescence was measured at GloMax ${ }^{\circledR}$-Multi Microplate Reader (Promega, Madison, USA) and percentage of viability was calculated as follows:

$$
\begin{aligned}
& \text { Cytotoxicity (\%) } \\
& \qquad=\left[\left(\frac{\text { FI } 590 \text { of treated samples }}{\text { FI } 590 \text { of untreated cells }}\right)(100)\right]
\end{aligned}
$$


where FI $590=$ fluorescent intensity at $590 \mathrm{~nm}$ emission $(560$ nm excitation).

The lethal concentration 50 (LC50) was determined by semilog graph plotted as percent of untreated control for each BG and BGAg suspensions.

2.5. PMNs Viability Assay. Cell death was assayed by the LIVE/DEAD ${ }^{\mathrm{TM}}$ viability/cytotoxicity kit (Thermo Fisher, Rockford, IL, USA) according to kit instructions. Briefly, $10^{5}$ PMNs were incubated with BG and BGAg samples for 4 hours at $37^{\circ} \mathrm{C}$ in a humidified atmosphere at $5 \% \mathrm{CO}_{2}$. Cells were incubated with $80 \%$ methanol for death control. Twenty minutes after staining with $1 \mu \mathrm{M}$ calcein and ethidium homodimer, fluorescence visualization was performed using epifluorescence microscope EVOS FL cell imaging system (Life Technologies, Eugene, OR, USA) equipped with a 40x objective, GFP and RFP filter cubes. Quantification of live and dead cells was analyzed in 3 aleatory fields using Image (National Institutes of Health, Bethesda, MD) software according to recommendations [23].

2.6. Luminol-Enhanced Chemiluminescence Assay. Production of intra- and extracellular ROS was analyzed by luminolenhanced chemiluminescence. Briefly, the PMN suspension $\left(2 \times 10^{5}\right.$ cells $\left./ \mathrm{ml}\right)$ was incubated for $45 \mathrm{~min}$ at $37^{\circ} \mathrm{C}$ and $5 \%$ $\mathrm{CO}_{2}$ with the BG and BGAg samples in white polystyrene 96wells flat bottom (Greiner Bio-One, USA). Serum-opsonized zymosan (final concentration of 1,62 mg/ml; Sigma-Aldrich, St. Louis, USA) or medium alone were the positive and negative control, respectively. After incubation, $10^{-4} \mathrm{M}$ luminol (Sigma-Aldrich, St. Louis, USA) was added and chemiluminescence was measured at 2-minute intervals with a luminometer GloMax ${ }^{\circledR}$-Multi Microplate Reader (Promega, Madison, USA) for a period of $1 \mathrm{~h}$ at $37^{\circ} \mathrm{C}$. Chemiluminescence was expressed as relative light units (RLU) and the area under the curve (AUC) was determined for each stimulus.

2.7. Quantification of Cytokine Release. PBMCs $\left(10^{6}\right.$ cells $\left./ \mathrm{ml}\right)$ were cultured for 24 hours at 48 -well plates with the larger subtoxic concentration $(0.031 \%$ for $\mathrm{BG}$ and $0.0008 \%$ for $\mathrm{BGAg}$ ) at $37^{\circ} \mathrm{C}$ in $5 \% \mathrm{CO}_{2}$. In order to induce the maximum PBMC activation and release of largest mediators amounts, PHA was used as in vitro model of immune cells stimulation [24]. Then, the supernatants of PBMCs cultures (with or without $5 \mu \mathrm{g} / \mathrm{ml}$ PHA stimulation) were analyzed for IL- $1 \beta$, TNF- $\alpha$, IL-4, IL-6, and IL-10 concentrations by sandwich ELISA assay using OptEIA Kit (Becton Dickinson, Franklin Lakes, New Jersey, USA) according to kit protocol.

2.8. Statistical Analysis. Significant differences on cell viability, cytokine production, and ROS release between the groups were determined by Kruskal Wallis test with Dunn's post hoc $(\alpha=0.05)$ using the software GraphPad Prism 7 (GraphPad Software Inc., San Diego, USA).

\section{Results and Discussion}

3.1. Cell Viability in the Presence of BG and BGAg. With the objective of observing acute cytotoxicity, cell viability of
PBMC was accessed after $24 \mathrm{~h}$ incubation with BG and BGAg by determining the metabolic capacity of cells to reduce the indicator dye resazurin to fluorescent resorufin. A dosedependent reduction in cell viability was observed in both samples of BG (Figure 1). The cell viability decreased to values less than $50 \%$ of control cells at the highest treatment concentration of 0.125 and $0.0075 \%$ for BG and BGAg, respectively. Calculated LC50 values were $0.106 \%$ for BG and $0.005 \%$ for BGAg.

Over the range of $\mathrm{BG}$ concentrations, BG $0.031 \%$ was the highest value that did not compromise PBMC viability in comparison to growth control $(\mathrm{P}>0.05)$. This result is above the subtoxic concentration of $0.01 \%$ observed in a previous work [16]. The range of BGAg concentrations $1-0,0016 \%$ had a drastic effect on PBMC viability. Notably, the BGAg nontoxic concentration was $0.0008 \%(\mathrm{P}>0.05)$ when compared with the control cells.

Therefore, these remarkable differences in cytotoxicity of the BG and BGAg against PBMCs might be associated with free $\mathrm{Ag}^{2+}$ in culture medium. An earlier study demonstrated that $\mathrm{Ag}^{2+}$ cytotoxicity against PBMCs was dose- and timedependent [15]. BG and BGAg subtoxic doses in PBMCs did not influence the PMN viability according to LIVE/DEAD. Fluorescence images of PMN cultures stained with ethidium homodimer (damaged cell marker) did not show quantitative differences between sample wells and growth control wells (Figure 2). For avoiding PMN death due the natural shortlived cell cycle, the cell viability was quantified after incubation of 4 hours.

The discrepant results in PBMC viability may be explained by silver addiction at BG synthesis and its release in culture medium. The ion in question can induce inflammation, cell activation and oxidative stress, ROS production, protein inactivation, inhibition of respiratory chain dehydrogenase, alteration of ionic channels, misbalance of cations/anions metabolism, organelle, and DNA damage $[17,25,26]$. The soluble Ag2+ can form complexes with biomolecules causing protein dysfunction and loss of enzyme activity (inactivation, loss of tertiary structure, replacement of cofactors, exchange of structural metals, breakage of disulfide bonds, among others), impaired membrane function caused by the loss of membrane potential, mechanical damage, and interference with nutrient uptake [25]. Taken together, these events lead to cell wall breakdown and cytolysis [26]. Further probes aiming to evaluate cellular growth inhibition and quantifies cell populations as healthy, dead, apoptotic, or necrotic when exposed to BG and BGAg under different conditions of time and concentrations are necessary to complete enlighten the cytotoxic mechanism of modified bioactive glasses.

Despite undesirable effects to human cells, silver-doped glasses produced under sol-gel method were bactericidal to Staphylococcus aureus and E. coli but not toxic to human osteoblasts, under controlled concentrations [14]. Other studies [27] demonstrated growth inhibition of S. aureus, E. coli, and $P$. aeruginosa cultures under $\mathrm{Ag}^{2+}$ released in medium by silver-doped bioactive glasses. The antibacterial mechanism of the silver-doped bioactive glass was investigated before 


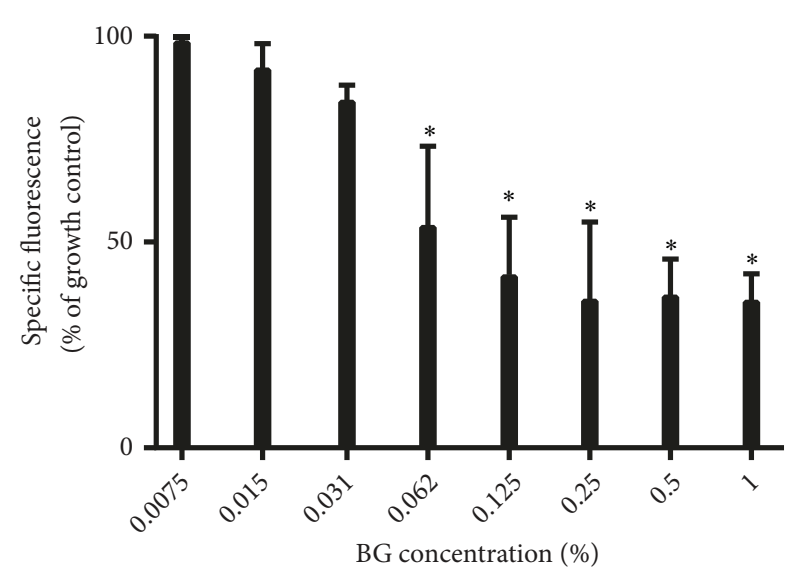

(a)

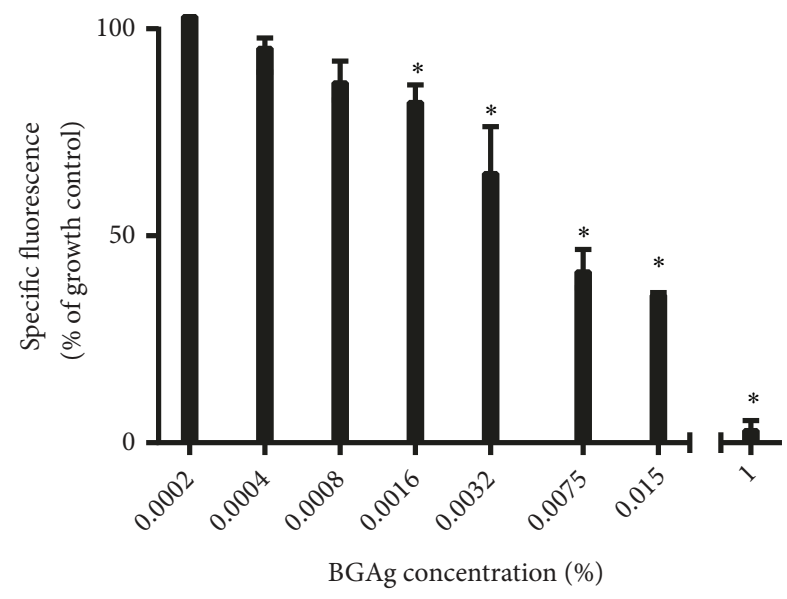

(b)

Figure 1: BG (a) and BGAg (b) effects on PBMC viability. Cell viability after treatment with increasing concentrations of BG and BGAg expressed as percentage of baseline viability. Results are shown as median with $95 \%$ confidence interval (CI) of an experiment performed in triplicate of each volunteer $\left({ }^{*} \mathrm{P}<0.05\right.$ compared to growth control).

E. coli and S. aureus strains had DNA damage and protein denaturation compromising cellular growth [28].

Opportunistic Gram-positive staphylococci are appointed as cause of approximately $75 \%$ of osteomyelitis cases, while the most severe infections are caused by Staphylococcus aureus [29]. The repair of such infected bone defects is a concern in implantology and orthopedics areas. To avoid such complication and offer more predictable treatment outcomes, the association between antibacterial and osteoinductive properties is encouraged. Local delivery of alternative antimicrobials has advantages over to systemic antibiotics: broader bactericidal spectrum and nearly no resistance $[30,31]$. Prevention methods as coating on implants and antimicrobial materials application are key to prevent osteomyelitis [29].

In addition, Pires et al. [18] observed that the present BGAg samples, instead of neat BG, exhibited therapeutic potential to treat infections caused by Leishmania parasites. The growth and proliferation inhibition of promastigote and metacyclic infective forms of the parasites occurred in the presence of $0,003 \% \mathrm{BGAg}$. In parallel to that study, the BGAg effective concentration allowed a PBMC viability of $65.5 \%$ after 24 hours of incubation. However, for other cell types, e.g., osteoblasts and fibroblasts, this relationship between therapeutic concentrations and cell viability lacks definition.

3.2. Oxidative Stress. Both samples of BG and BGAg alone were unable to induce intra- and extracellular ROS production above baseline parameters (Figure 3). Therefore, the higher dilution of neat BG decreased ROS detection when coincubated with opsonized zymosan. This compound activates an oxidative burst by binding itself to complement receptors, leading transduction signal to protein kinase $\mathrm{C}$ activation and consequent activation of NADPH-oxidase, the key enzyme of oxidative burst [32]. The oxidative stress reduction could be explained by the following: BG dissolved products like silica, calcium, phosphate, and sodium ions contribute to the balance of the oxidative status, or they may interfere with zymosan-receptor complex, or they might have the ability to act as free radicals and superoxides scavengers. The in vivo redox activity of bioglass compounds was previously reported [30]; thus the exact mechanism of action is still not clear. Such modulatory effect is of great relevance in osteogenesis by induction of osteoblasts metabolism and differentiation.

On the other hand, ROS production is a common finding on in vitro and in vivo models due to $\mathrm{Ag}$ presence in different biological systems. Overproduction of free radicals is appointed as a mechanism of cytotoxicity by oxidative stress, resulting in genotoxicity and cells breakdown [25]. BGAg samples unhanged ROS levels in culture medium; this finding may justify why the concentrations applied were not cytotoxic for PMN's cultures.

3.3. Cytokine Modulation. Quantification of TNF- $\alpha$, IL- $1 \beta$, IL-6, and IL-10 at 24h PBMC's culture supernatant performed by sandwich ELISA showed no significant differences between the treatments with three subtoxic BG and BGAg suspensions and baseline control (Figure 4). At some sample concentrations, TNF- $\alpha$, IL-1 $\beta$, and IL-10 release were lower than detection limits of the method. Interestingly, however, all BG and BGAg samples induced IL-4 production to similar levels than PHA stimulus (Figure 4). This result cannot be attributed to the action of biomaterials since the production of IL-4 by unstimulated cells was not significantly different. The presence of bioactive glasses did not change TNF- $\alpha$, IL$1 \beta$, IL-6, and IL-10 secretion profile compared to basal levels or PHA stimulated cells. These results suggest that bioactive glasses particles even when doped with silver ions do not change the levels of releasing proinflammatory and antiinflammatory cytokines by human PBMC.

Immunomodulatory effects of bioactive glasses were investigated by previous studies. Particles belonging to system 60 S did not change significantly IL-4 secretion profile 


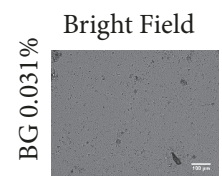

(A)

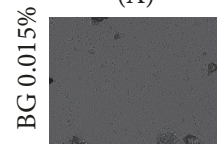

(E)

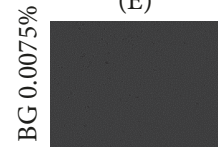

(I)

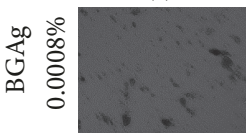

(M)

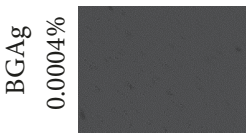

(Q)

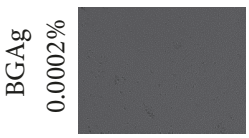

(U)

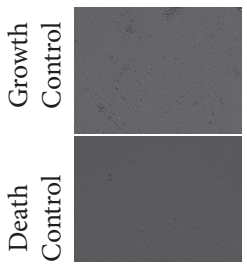

GFP

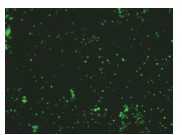

(B)

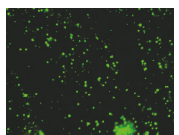

(F)

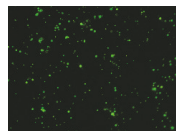

(J)

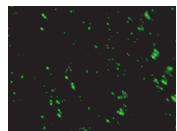

(N)

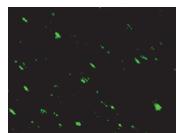

(R)

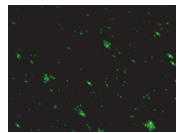

(V)

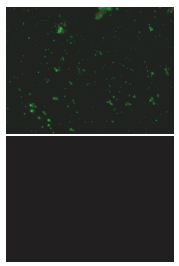

(a)
RFP

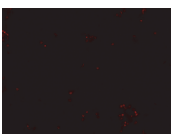

(C)

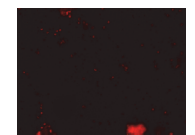

(G)

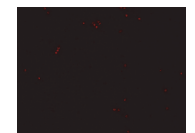

(K)

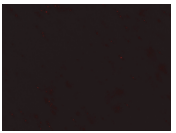

(O)

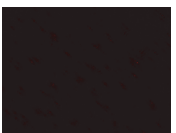

(S)

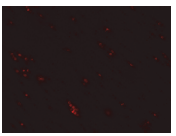

(X)

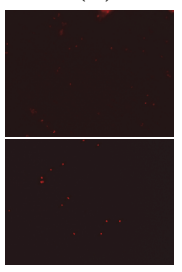

MERGE

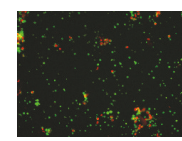

(D)

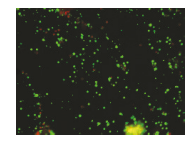

(H)

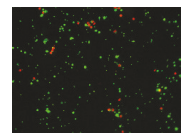

(L)

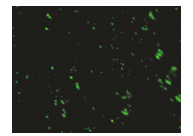

(P)

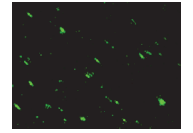

(T)

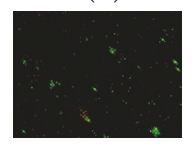

(Z)
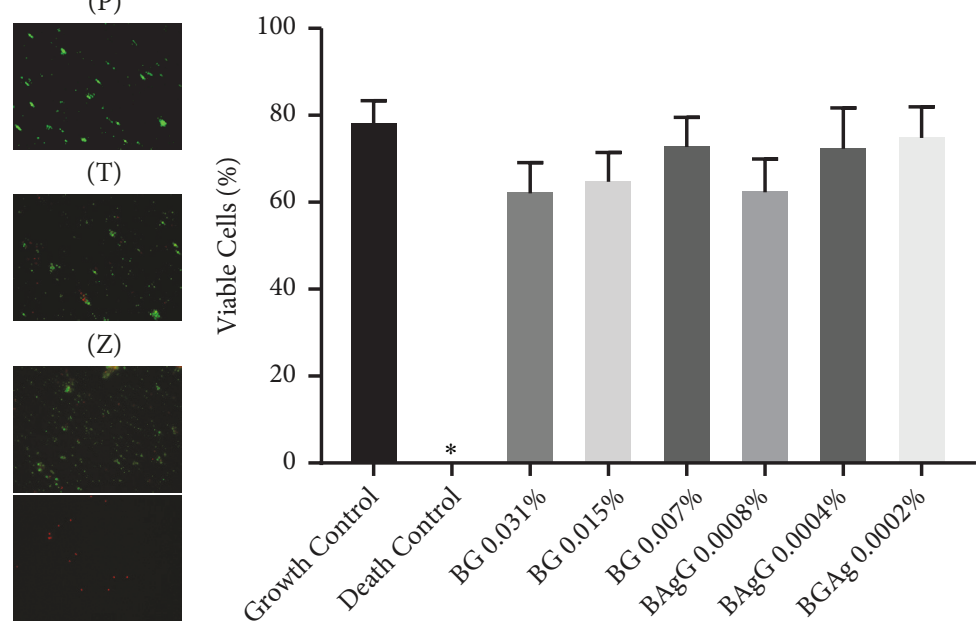

(b)

FIGURE 2: PMN viability in presence of $B G(A-L)$ and $B G A g(M-Z)$. Demonstrative images of Live/Dead ${ }^{\mathrm{TM}}$ assay captured by $40 \mathrm{x}$ objective (a). The bright field shows cell morphology, GFP shows live cells green stained by calcein, and RFP shows dead cells stained by ethidium homodimer. For growth and death controls, cells were incubated, respectively, with, medium alone or $80 \%$ methanol. (b) Percentage of viable PMNs were counted on three aleatory fields. PMNs incubated with different concentrations of BG and BGAg have a similar number of viable cells compared to growth control. Results were expressed as median with $95 \% \mathrm{CI}\left({ }^{*} \mathrm{P}<0.05\right.$ compared to growth control).

by PBMCs [33]. In agreement with our current results, other studies found that $45 \mathrm{~S} 5$ glass did not interfere with IL-6, IL-10, and TNF- $\alpha$ secretion by nonstimulated macrophages and monocytes cultures [7]. This same study observed a decrease in TNF- $\alpha$ production when the cells were incubated with LPS. On the other hand, another study showed that 45S5 powders upregulated TNF- $\alpha$ secretion by peritoneal macrophages [34]. Beyond cell population variances, differences on cytokine modulation may be explained by different factors that induce immune response by biomaterials, such as BG composition, particle size, surface chemistry, plasma protein binding, and exposure model [35].

The literature has a great extended relates about therapeutic perspectives for bioactive glasses, including implant coatings, alloplastic grafts for sinus lift (micro particles formulation) or replacement after tumor removal (scaffolds), and dental composites [3]. Beyond the hard tissues engineering, bioactive glasses can also be applied in the soft tissue manipulation. Several studies report on the application of BGs for wound healing by mechanisms of stimulation of angiogenesis, establishment of bg-collagenous bonding, and accelerated rate of blood coagulation [36]. The described biological properties are relevant in the context of management of chronic wounds including, for example, diabetic foot ulcers, venous leg ulcers, and pressure ulcers [37].

In some therapies against cancer, arthritis, and allergies, an immunomodulatory capacity of the therapeutic agent is highly desirable. However, an unbalanced immunosuppression or immunostimulation might be associated with many of the undesirable side effects observed in most cases. Thus, the study of interactions between biomaterials and the immune system is key for safe medicinal use of recently developed 

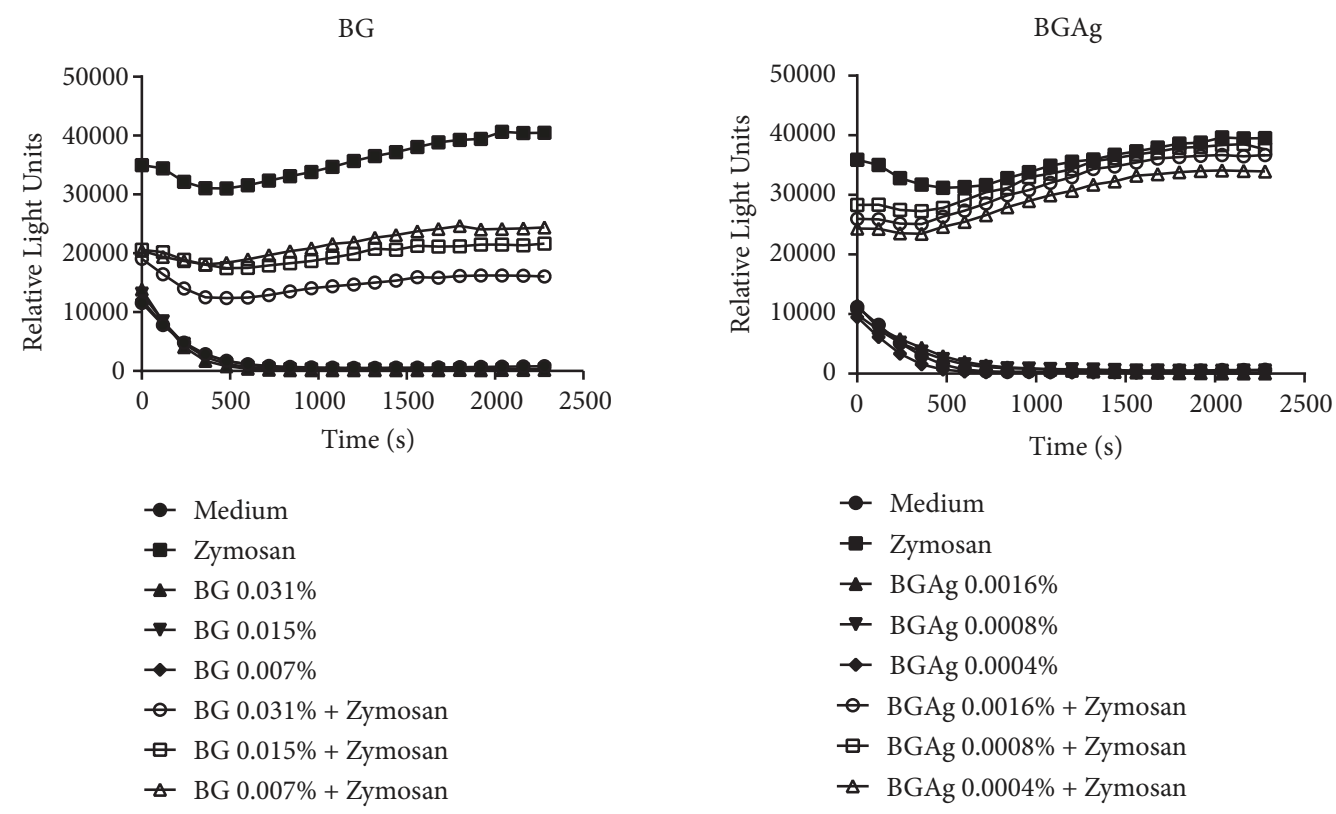

(a)

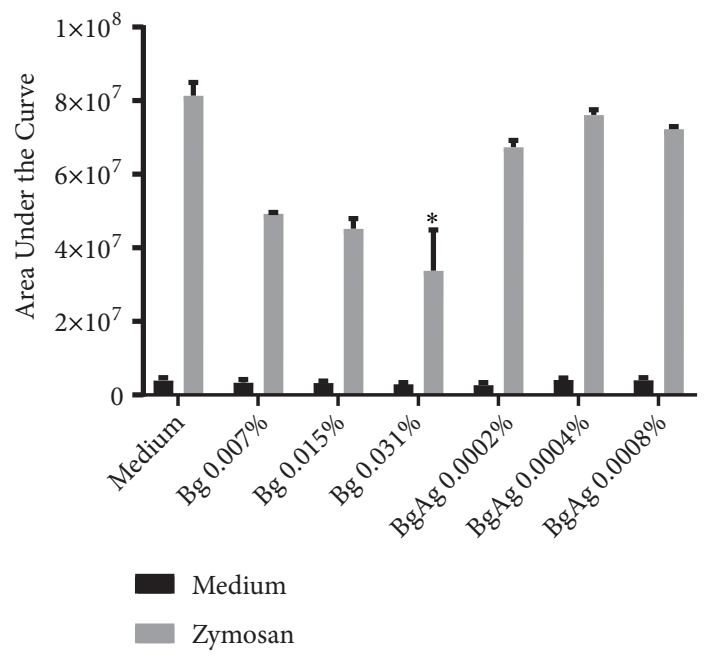

(b)

FIGURE 3: ROS production in PMNs. (a) Chemiluminescent curves showing similar relative light units (RLU) detection between BG and BGAg samples when compared to with negative control (medium only). BG samples decreased ROS production when coincubated with zymosan (positive control). Each point represents the median of triplicate readings of ex vivo PMN cultures $(n=3)$. (b) Area under the curve (AUC) values plotted for each stimulus. The sample BG $0.031 \%$ reduced significantly ROS production in comparison with only zymosan as stimulus. Values were expressed as median with $\mathrm{CI}\left({ }^{*} \mathrm{P}<0.05\right.$ compared to positive control).

biomaterials. A recent work questioned the actual capacity to examine the real function of biomaterials within both innate and adaptive immune responses, mainly concerning the $\mathrm{B}$ and $\mathrm{T}$ cell responses [38]. Although models for determining acute and long-term immune toxicities have been developed, studies on the treatment and prediction of immunomodulatory activity are scarce $[35,38]$. One study showed that some biomaterials modified the adaptive immunity (cell phenotype and cytokine release) and promoted tissue repair [39]. Our results follow these studies which contribute to expanding the knowledge about materials science and biomedical engineering applications in humans [40].

\section{Conclusions}

The presence of silver increased the glass cytotoxicity against human PBMCs. The 58S BG and BGAg subtoxic concentrations did not interfere with patterns associated with release of main regulatory, pro- and anti-inflammatory cytokines by cultured PMBCs. Both BG and BGAg were unable to induce 


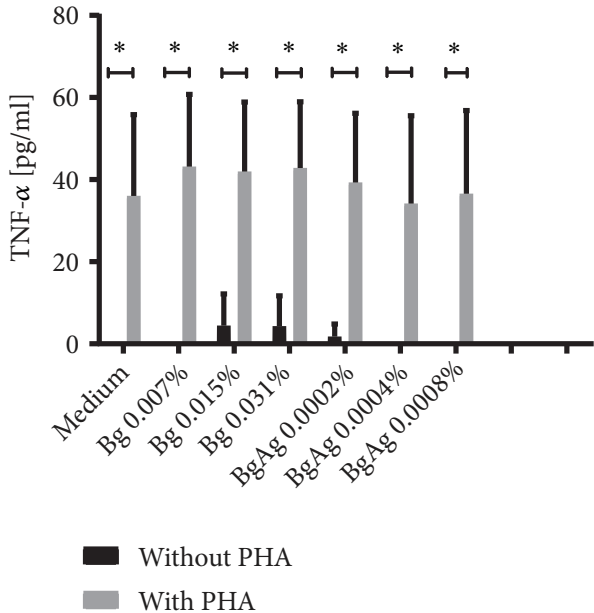

(a)

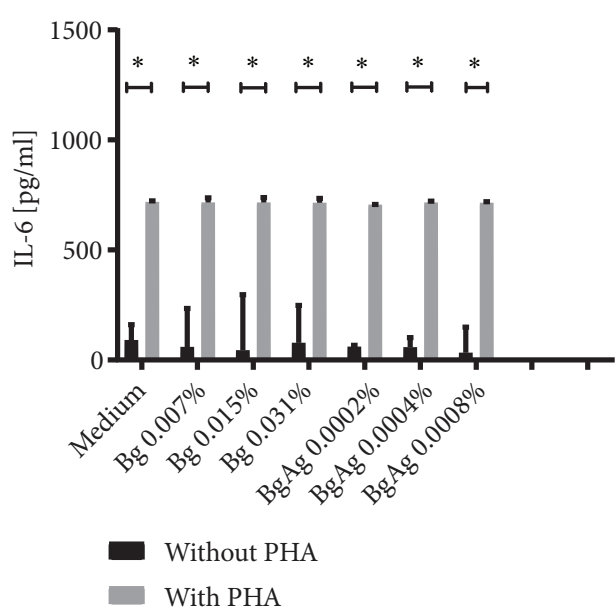

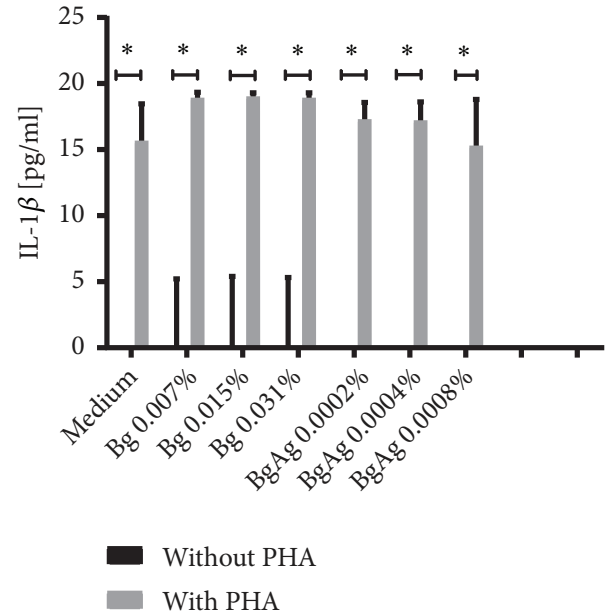

(b)

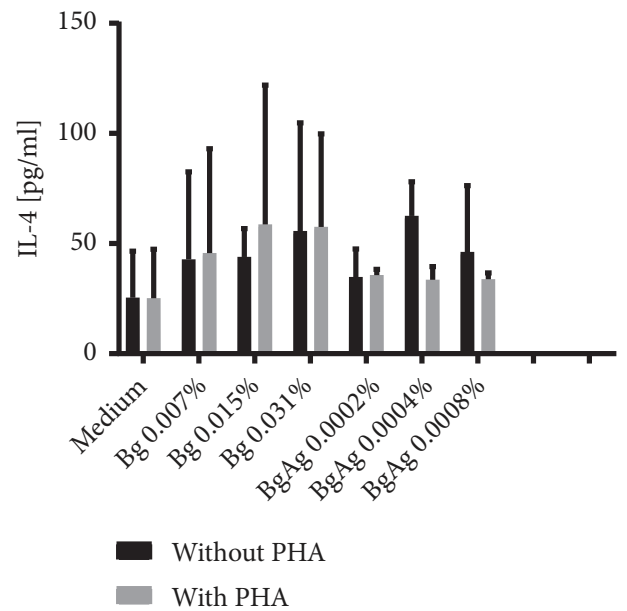

(d)

(c)

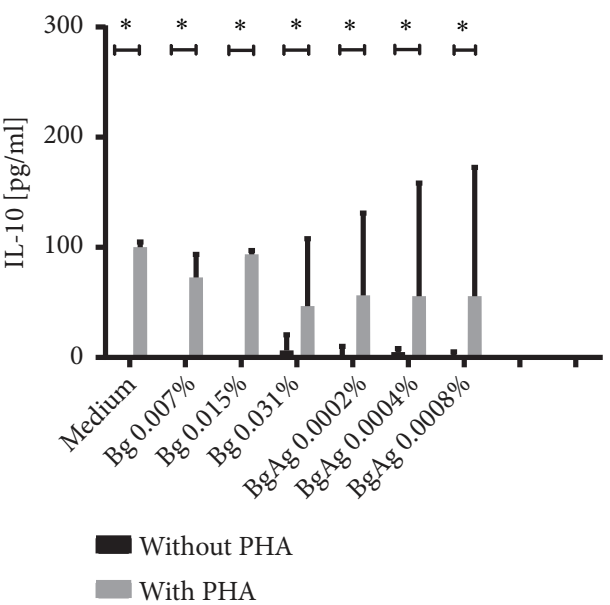

(e)

Figure 4: Cytokine release by PBMC cultures incubated with BG or BGAg. Titration of TNF- $\alpha$ (a), IL-1 $\beta$ (b), IL-6 (c), IL-4 (d), and IL-10 (e) released at 24-hour culture supernatant of PBMC's cultured with or without $5 \mu \mathrm{g} / \mathrm{ml}$ PHA stimulation. There were no significant differences on cytokine's production between BG and BGAg stimulus and medium alone treatment. Bioactive glasses were unable to reduce cytokine levels after PHA coincubation. ${ }^{*}$ Correspond to the statistical difference $(\mathrm{p}<0,05)$. Data were presented as the median $\pm 95 \% \mathrm{CI}$ of triplicates of each volunteer $(n=3)$. 
ROS production, while neat BG decreased ROS production when coincubated with serum-opsonized zymosan, suggesting its potential scavenger activity. Further studies of silver dissolution in culture medium, in vivo $\mathrm{Ag}^{+}$biodistribution and the development of mechanisms for ion release control according to desirable dose are necessary and important next steps to increase our current knowledge about therapeutic applications of BG and BGAg.

\section{Data Availability}

Previously reported BG and BGAg synthesis and characterization data were used to support this study and are available at https://doi.org/10.1111/ijag.12285. This prior study is cited at relevant places within the text as [18].

\section{Ethical Approval}

This study was approved by the Research Ethics Committee of the Universidade Federal da Paraíba under Protocol no. 61192816.6.0000.5188.

\section{Consent}

All study participants signed an informed consent in accordance to the Resolution 466/2012 from the Brazilian National Council of Health.

\section{Disclosure}

The main findings of the study have been presented in poster format at the Academy of Dental Materials Annual Meeting 2018 and the abstract is available at https://doi.org/10.1016/j.dental.2018.08.050.

\section{Conflicts of Interest}

The authors declare that the research was conducted in the absence of any commercial or financial relationships that could be construed as potential conflicts of interest.

\section{Acknowledgments}

This study was financially supported by the Universidade Federal da Paraíba, Coordenação de Aperfeiçoamento de Pessoal de Nível Superior (CAPES, Brazil, fellowship to JL), and Conselho Nacional de Desenvolvimento Científico eTecnológico (CNPq, Brazil)/INCT-TeraNano (Grant no. 465669/2014-0). In addition, we are grateful to Rebeca Tibau, MSc, for technical support during the study.

\section{References}

[1] V. J. Shirtliff and L. L. Hench, "Bioactive materials for tissue engineering, regeneration and repair," Journal of Materials Science, vol. 38, no. 23, pp. 4697-4707, 2003.

[2] L. L. Hench, R. J. Splinter, W. C. Allen, and T. K. Greenlee, "Bonding mechanisms at the interface of ceramic prosthetic materials," Journal of Biomedical Materials Research Part B: Applied Biomaterials, vol. 5, no. 6, pp. 117-141, 1971.

[3] J. R. Jones, L. M. Ehrenfried, and L. L. Hench, "Optimising bioactive glass scaffolds for bone tissue engineering," Biomaterials, vol. 27, no. 7, pp. 964-973, 2006.

[4] G. Chouzouri and M. Xanthos, "In vitro bioactivity and degradation of polycaprolactone composites containing silicate fillers," Acta Biomaterialia, vol. 3, no. 5, pp. 745-756, 2007.

[5] A. Al-Noaman, S. C. F. Rawlinson, and R. G. Hill, "Bioactive glass-stoichimetric wollastonite glass alloys to reduce TEC of bioactive glass coatings for dental implants," Materials Letters, vol. 94, pp. 69-71, 2013.

[6] A. Al-Noaman, N. Karpukhina, S. C. F. Rawlinson, and R. G. Hill, "Effect of FA addition on bioactivity of bioactive glass coating for titanium dental implant: Part II- Composite coating," Journal of Non-Crystalline Solids, vol. 364, pp. 99-106, 2013.

[7] R. M. Day, A. R. Boccaccini, S. Shurey et al., "Assessment of polyglycolic acid mesh and bioactive glass for soft-tissue engineering scaffolds," Biomaterials, vol. 25, no. 27, pp. 58575866, 2004.

[8] C. Lin, C. Mao, J. Zhang, Y. Li, and X. Chen, "Healing effect of bioactive glass ointment on full-thickness skin wounds," Biomedical Materials, vol. 7, no. 4, Article ID 045017, 2012.

[9] L. L. Hench and J. R. Jones, "Bioactive glasses: frontiers and challenges," Frontiers in Bioengineering and Biotechnology, vol. 3, 2015.

[10] A. Balamurugan, G. Balossier, D. Laurent-Maquin et al., "An in vitro biological and anti-bacterial study on a sol-gel derived silver-incorporated bioglass system," Dental Materials, vol. 24, no. 10, pp. 1343-1351, 2008.

[11] H. Zhu, C. Hu, F. Zhang et al., "Preparation and antibacterial property of silver-containing mesoporous 58 S bioactive glass," Materials Science and Engineering C: Materials for Biological Applications, vol. 42, pp. 22-30, 2014.

[12] A. A. El-Rashidy, G. Waly, A. Gad et al., "Antibacterial activity and biocompatibility of zein scaffolds containing silver-doped bioactive glass," Biomedical Materials, vol. 13, no. 6, Article ID 065006, 2018.

[13] F. Baghbani, F. Moztarzadeh, M. Mozafari, M. Raz, and H. Rezvani, "Production and characterization of a Ag- and $\mathrm{Zn}$-doped glass-ceramic material and in vitro evaluation of its biological effects," Journal of Materials Engineering and Performance, vol. 25, no. 8, pp. 3398-3408, 2016.

[14] A. M. El-Kady, A. F. Ali, R. A. Rizk, and M. M. Ahmed, "Synthesis, characterization and microbiological response of silver doped bioactive glass nanoparticles," Ceramics International, vol. 38, no. 1, pp. 177-188, 2012.

[15] M. M. Abudabbus, I. Jevremović, A. Janković et al., "Biological activity of electrochemically synthesized silver doped polyvinyl alcohol/graphene composite hydrogel discs for biomedical applications," Composites Part B: Engineering, vol. 104, pp. 26$34,2016$.

[16] R. M. Day and A. R. Boccaccini, "Effect of particulate bioactive glasses on human macrophages and monocytes in vitro," Journal of Biomedical Materials Research Part A, vol. 73, no. 1, pp. 73-79, 2005.

[17] I. M. M. Paino and V. Zucolotto, "Poly(vinyl alcohol)-coated silver nanoparticles: Activation of neutrophils and nanotoxicology effects in human hepatocarcinoma and mononuclear cells," Environmental Toxicology and Pharmacology, vol. 39, no. 2, pp. 614-621, 2015. 
[18] E. G. Pires, R. F. Bonan, Í. M. Rocha et al., "Silver-doped $58 \mathrm{~S}$ bioactive glass as an anti-Leishmania agent," International Journal of Applied Glass Science, 2017.

[19] G. Katara, N. Hemvani, S. Chitnis, V. Chitnis, and D. Chitnis, "Surface disinfection by exposure to germicidal UV light," Indian Journal of Medical Microbiology, vol. 26, no. 3, pp. 241242, 2008.

[20] S. Janetzki, C. M. Britten, M. Kalos et al., “'MIATA'-minimal information about T cell assays," Immunity, vol. 31, no. 4, pp. 527-528, 2009.

[21] C. F. Arkin, J. D. Bessman, R. R. Calam, D. J. Ernst, G. T. Parish, and D. I. Szamosi, "Procedures for the collection of diagnostic blood specimens by venipuncture; approved standard," Clinical and Laboratory Standards Institute, vol. 23, no. 32, p. 52, 2003.

[22] L. R. Castellano, D. C. Filho, L. Argiro et al., “Th1/Th2 immune responses are associated with active cutaneous leishmaniasis and clinical cure is associated with strong interferon- $\gamma$ production," Human Immunology, vol. 70, no. 6, pp. 383-390, 2009.

[23] P. Spaepen, S. De Boodt, J.-M. Aerts, and J. V. Sloten, "Digital image processing of live/dead staining," Mammalian Cell Viability: Methods and Protocols, vol. 740, pp. 209-230, 2011.

[24] D. Rendina, C. Ryff, and C. Coe, "Concordance of serum cytokines and stimulated mononuclear cell responses in older adults," Brain, Behavior, and Immunity, vol. 49, p. e39, 2015.

[25] J. A. Lemire, J. J. Harrison, and R. J. Turner, "Antimicrobial activity of metals: mechanisms, molecular targets and applications," Nature Reviews Microbiology, vol. 11, no. 6, pp. 371-384, 2013.

[26] Y.-H Hsueh, K.-S Lin, W.-J Ke et al., "The antimicrobial properties of silver nanoparticles in bacillus subtilis are mediated by released Ag+ ions," PLoS ONE, vol. 10, no. 12, p. e0144306, 2015.

[27] M. Bellantone, H. D. Williams, and L. L. Hench, "Broadspectrum bactericidal activity of Ag2O-doped bioactive glass," Antimicrobial Agents and Chemotherapy, vol. 46, no. 6, pp. 1940-1945, 2002.

[28] Q. L. Feng, J. Wu, G. Q. Chen, F. Z. Cui, T. N. Kim, and J. O. Kim, "A mechanistic study of the antibacterial effect of silver ions on Escherichia coli and Staphylococcus aureus," Journal of Biomedical Materials Research Part B: Applied Biomaterials, vol. 52, no. 4, pp. 662-668, 2000.

[29] G. Walter, M. Kemmerer, C. Kappler, and R. Hoffmann, "Treatment algorithms for chronic osteomyelitis," Deutsches Ärzteblatt International, vol. 109, no. 14, pp. 257-264, 2012.

[30] J. A. Inzana, E. M. Schwarz, S. L. Kates, and H. A. Awad, "Biomaterials approaches to treating implant-associated osteomyelitis," Biomaterials, vol. 81, pp. 58-71, 2016.

[31] H. Lu, Y. Liu, J. Guo, H. Wu, J. Wang, and G. Wu, "Biomaterials with antibacterial and osteoinductive properties to repair infected bone defects," International Journal of Molecular Sciences, vol. 17, no. 3, p. 334, 2016.

[32] S. Sergeant and L. C. McPhail, "Opsonized zymosan stimulates the redistribution of protein kinase $\mathrm{C}$ isoforms in human neutrophils," The Journal of Immunology, vol. 159, no. 6, pp. 2877-2885, 1997.

[33] C. Silva, A. Bozzi, M. Pereira, A. Goes, and M. F. Leite, "Effects of bioactive glass $60 \mathrm{~S}$ and biphasic calcium phosphate on human peripheral blood mononuclear cells," in Key Engineering Materials, vol. 254-256, pp. 841-844, Trans Tech Publisher, 2004.

[34] M. Bosetti, L. Hench, and M. Cannas, "Interaction of bioactive glasses with peritoneal macrophages and monocytes in vitro," Journal of Biomedical Materials Research Part B: Applied Biomaterials, vol. 60, no. 1, pp. 79-85, 2002.
[35] Q. Jiao, L. Li, Q. Mu, and Q. Zhang, "Immunomodulation of nanoparticles in nanomedicine applications," BioMed Research International, vol. 2014, Article ID 426028, 19 pages, 2014.

[36] V. Miguez-Pacheco, L. L. Hench, and A. R. Boccaccini, "Bioactive glasses beyond bone and teeth: Emerging applications in contact with soft tissues," Acta Biomaterialia, vol. 13, pp. 1-15, 2015.

[37] R. G. Frykberg and J. Banks, "Challenges in the treatment of chronic wounds," Advances in Wound Care, vol. 4, no. 9, pp. 560-582, 2015.

[38] A. Vishwakarma, N. S. Bhise, M. B. Evangelista et al., "Engineering immunomodulatory biomaterials to tune the inflammatory response," Trends in Biotechnology, vol. 34, no. 6, pp. 470-482, 2016.

[39] K. Sadtler, K. Estrellas, B. W. Allen et al., "Developing a proregenerative biomaterial scaffold microenvironment requires $\mathrm{T}$ helper 2 cells," Science, vol. 352, no. 6283, pp. 366-370, 2016.

[40] S. F. Badylak, "A scafold immune microenvironment," Science, vol. 352, no. 6283, p. 298, 2016. 


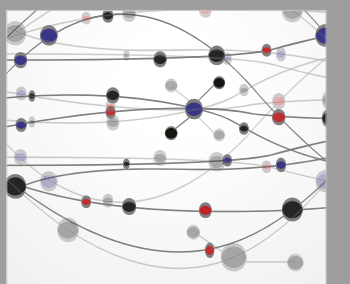

The Scientific World Journal
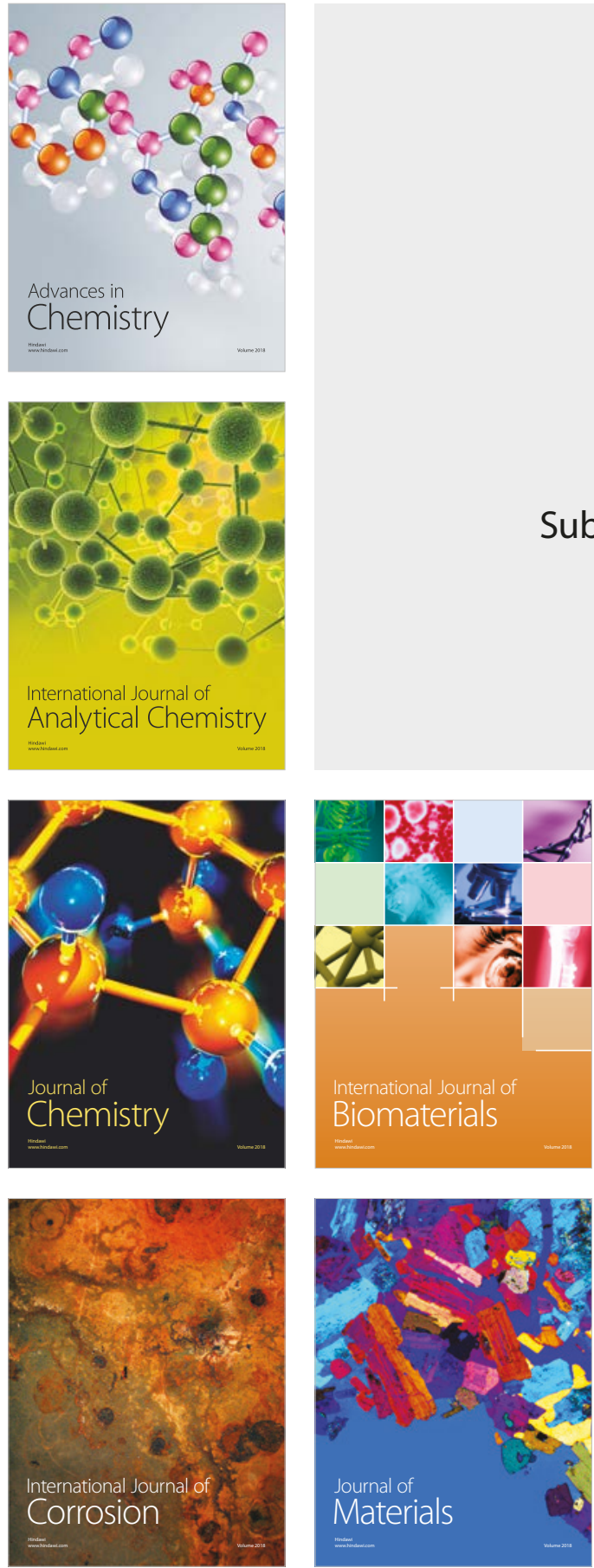

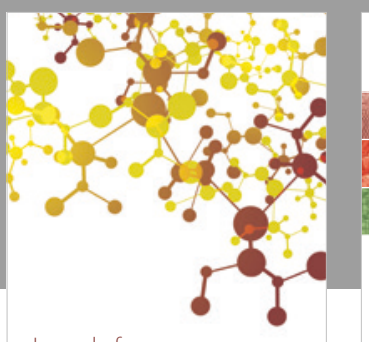

Journal of

Applied Chemistry
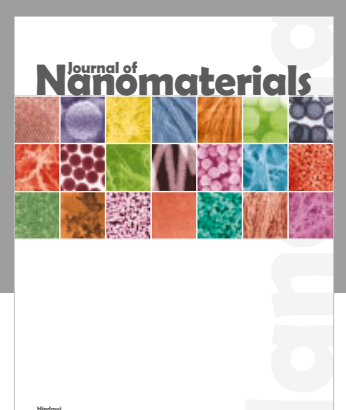

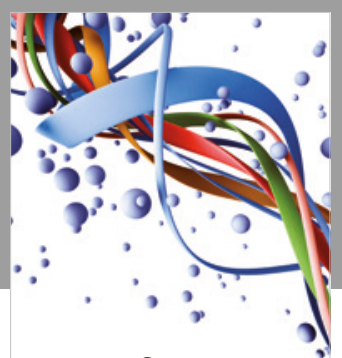

Scientifica

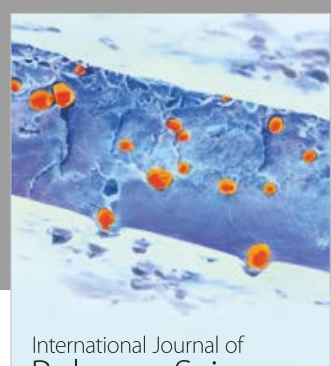

Polymer Science

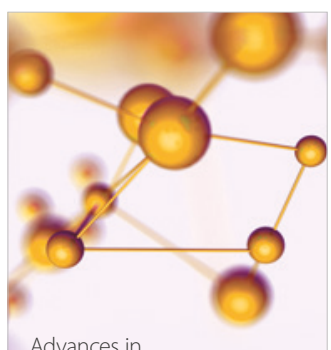

Physical Chemistry
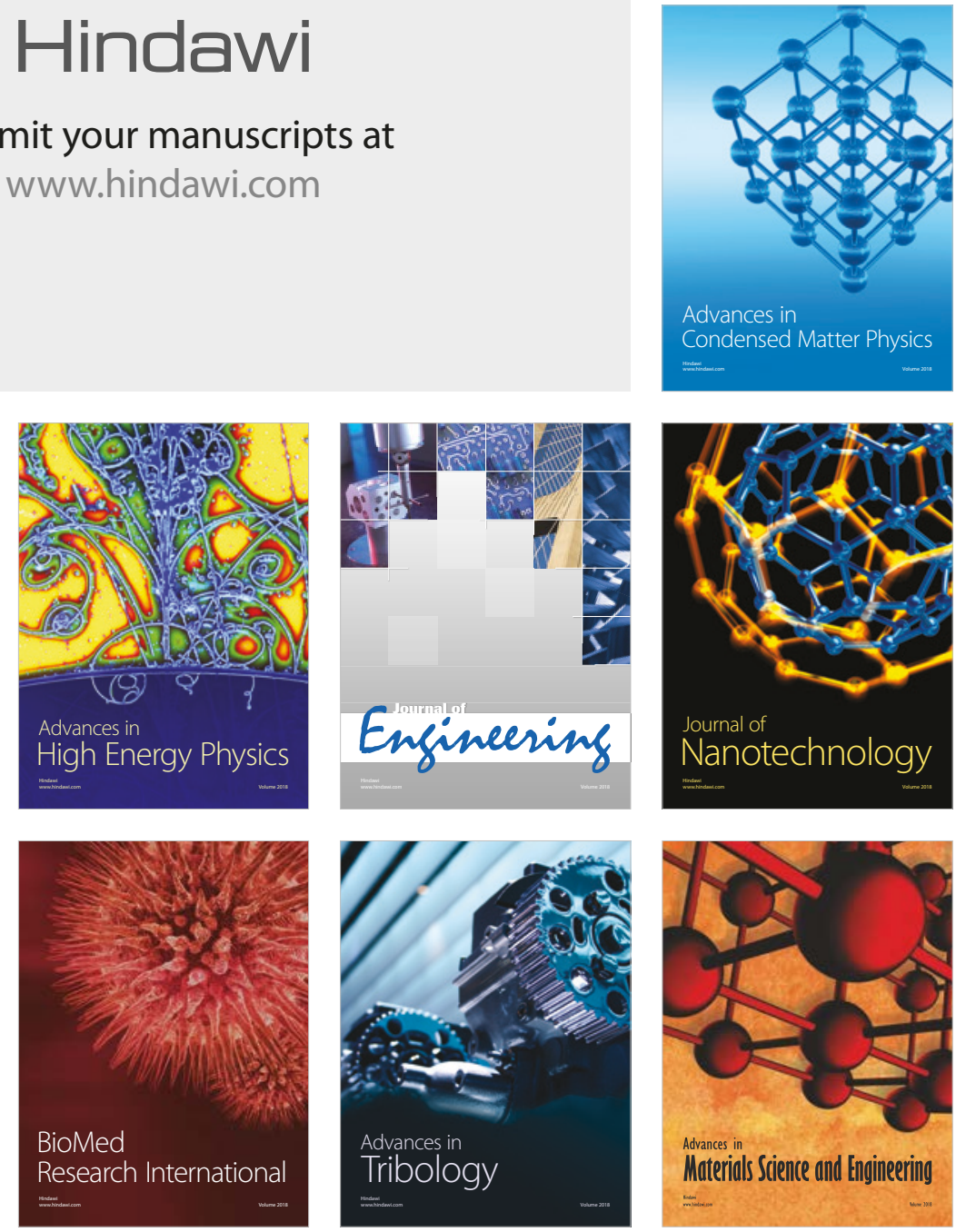